\title{
NUEVOS HOSPEDEROS Y REGISTROS DE ÁCAROS FITÓFAGOS PARA COSTA RICA: PERÍODO 2008-2012
}

\author{
Hugo Aguilar ${ }^{1 / *}$, Pamela Murillo*
}

\begin{abstract}
Palabras clave: Acari, Tetranychidae, Tenuipalpidae, Tarsonemidae, Eriophyidae, Phytoptidae, ácaros fitófagos.
\end{abstract} Keywords: Acari, Tetranychidae, Tenuipalpidae, Tarsonemidae, Eriophyidae, Phytoptidae, plant feeding mites.

Recibido: 17/07/12

\section{RESUMEN}

Se actualizan las especies de ácaros fitófagos identificadas para Costa Rica entre 2008 y 2012. Se procesó el material vegetal provisto por productores, técnicos, estudiantes e interesados en general, así como el recolectado por personal del Laboratorio de Acarología de la Universidad de Costa Rica, y se identificó. Se mencionan 63 nuevas especies en 29 familias de plantas hospedantes, para 5 familias de ácaros fitófagos. Tetranychus urticae, familia Tetranychidae, fue la segunda especie en cuanto a número de hospederos, encontrándose en 12 nuevas plantas. También se hallaron otras especies de la familia, como Eutetranychus banksi, Mononychellus planki, Oligonychus peronis, O. pratensis, O. punicae, O. ununguis, O. yothersi, Paraponychus corderoi, Tetranychus cinnabarinus, T. ludeni, T. mexicanus y 3 especies de este género que no fueron identificadas. Se registran 4 especies de la familia Tenuipalpidae: Brevipalpus californicus, B. gliricidiae, B. obovatus y B. phoenicis. Dentro de la familia Tarsonemidae, se informa de Phytonemus pallidus, Polyphagotarsonemus latus, con 15 nuevos registros, especie con mayor aporte en asociación con plantas para este nuevo período; se informa también de Steneotarsonemus ananas, asociada con piña. De la familia Eriophyidae, se indica de Abacarus doctus,

1 Autor para correspondencia. Correo electrónico: hugo.aguilar@ucr.ac.cr
Aceptado: 22/10/12 
descrita recientemente como nueva especie para la ciencia y asociada con caña de azúcar en el país y de Calepitrimerus muesebecki, relacionada con aguacate; además 2 especies de eriófidos expuestos, no descritas aún. Retracrus johnstoni, familia Phytoptidae, recolectado de Heliconia latispatha, de la familia Heliconiaceae y primer registro de un ácaro de este género asociado con una planta ajena a la familia Arecaceae. Por último, se expone la descripción del reconocimiento de campo para algunas especies escogidas dentro de las 5 familias estudiadas.

\section{INTRODUCCIÓN}

Los ácaros fitófagos muestran cada vez una mayor capacidad de adaptación a diversos ambientes y cada año se encuentran especies asociadas a nuevas plantas hospedantes. Halliday (2010) considera de gran valor identificar correctamente las especies de ácaros asociadas con cultivos de importancia económica, por razones relacionadas con la protección de plantas, bioseguridad y comercio internacional. Aguilar y Murillo (2008) publicaron una actualización de las nuevas plantas hospedantes de ácaros, para el período 2002-2008 en Costa Rica, encontrándose, en ese lapso, 159 nuevos registros de ácaros fitófagos agrupados en 52 familias de plantas.

Polyphagotarsonemus latus (Banks), es un organismo que desde hace muchos años se ha asociado con daños de consideración en una numerosa serie de cultivos en Costa Rica (Aguilar y Murillo 2008, Ochoa et al. 1991a y 1994). Diversos autores lo mencionan como dañino en cultivos nuevos en el país como el tempate, Jatropha curcas L.; especie en estudio para utilizarla en la producción de biodiesel (Quiroga et al. 2010).

El ácaro de 2 manchas, Tetranychus urticae Koch, es otra plaga acarina de gran relevancia,
Abacarus doctus, recently described as a new species, is reported associated with sugarcane in the country; likewise Calepitrimerus muesebecki, related to avocado, and 2 species of exposed, un-described eriophyids. Retracrus johnstoni, family Phytoptidae, was collected from Heliconia latispatha, family Heliconiaceae, first record of a mite in this genus associated with a family other than Arecaceae. Lastly, field diagnosis is also offered for some chosen species within the 5 families studied.

que causa daños en numerosos cultivos por todo el país. También se ha recolectado en plantas desarrolladas bajo condiciones de ambientes protegidos y en arvenses. En consecuencia, ambas plagas merecen un especial cuidado ya que, si se presentan las condiciones idóneas para su desarrollo, podrían llegar a ser devastadoras.

Oligonychus ununguis (Jacobi) es un ácaro asociado con coníferas, conocido como "Spruce spider mite", considerado como plaga de gran trascendencia económica en países de Norte América, Europa y aún en Australia (Tuttle et al. 1974, Gutierrez y Schicha 1983, Puchalska 2006, Danielsson 2011). En Polonia, por ejemplo, se informa que este ácaro está asociado con más de 90 especies de coníferas (Czajkowska y Puchalska 2006). Estas autoras consideran que lo que induce a $O$. ununguis a alimentarse de coníferas es la morfología, anatomía y componentes bioquímicos de la planta hospedante. En la región Neotropical, se informa asociado con Araucaria angustifolia (Bertol.) Kuntze, en Brasil (Fenilli y Flechtmann 1990). En Costa Rica se ha encontrado, recientemente, en una plantación de ciprés de 2 a 5 años. El daño también se ha observado en árboles con menos edad, así como en otros más desarrollados. En los países en donde se ha documentado la presencia de este ácaro, el ataque 
se considera como limitante dada su severidad en gran número de coníferas (Natural Resources Canada 2011, Czajkowska y Puchalska 2006).

Los ácaros planos, que pertenecen a la familia Tenuipalpidae, son encontrados con frecuencia, aunque no tanto como las arañitas y los ácaros blancos o tarsonémidos. Es Brevipalpus phoenicis (Geijskes) el que se halla con un poco más de periodicidad en cultivos como papaya (Carica papaya L.), guayaba (Psidium guajaba L.), ornamentales y cítricos (Citrus spp.) (Ochoa et al. 1991a y 1994, Aguilar y Murillo 2008, Rivero Maldonado et al. 2009, Urdaneta et al. 2009). Este ácaro se ha asociado con el virus de la leprosis de los cítricos en numerosos países; entre ellos, Brasil, Argentina, Paraguay, Venezuela, Panamá, Guatemala, México y Colombia (Childers y Rodrigues 2011). Hasta la fecha no se ha detectado la presencia del virus en Costa Rica y cualquier árbol sospechoso de presentar la enfermedad, es eliminado por orden de los funcionarios del Servicio Fitosanitario del Estado.

Por otro lado y, a pesar de la predicción hecha por expertos internacionales, hasta el momento, el ácaro rojo de las palmas, Raoiella indica Hirst, no ha sido localizado en Costa Rica. Como lo indicaron Aguilar y Murillo (2008), este es un ácaro de origen asiático, que se ha establecido en el Caribe y ha invadido países como Venezuela, Colombia, México, Brasil, Panamá y los Estados Unidos, en asocio principalmente con palmas de diversas especies y banano (Musa sp.) (Rodrigues et al. 2007, Vásquez et al. 2008, Peña et al. 2007, Flores-Galano et al. 2010, Kane y Ochoa 2010, Carrillo et al. 2011, Kane et al. 2012, Roda et al. 2012).

Según James Amrine, autoridad mundial en ácaros eriofioideos, en Costa Rica las especies de esta superfamilia encontradas asociadas con plantas y que no han sido descritas para la ciencia, deben estar entre un $95 \%$ y un $97 \%$; por lo tanto, el porcentaje de especies conocidas es muy bajo (J. Amrine. 2003. University of West Virgina. Comunicación personal). Los ácaros fitóptidos, pertenecientes también a la superfamilia Eriophyoidea, están representados por un número reducido de especies. En Costa Rica, se han informado únicamente las especies Retracrus elaeis Keifer en palma aceitera (Elaeis guineensis Jacq.) y pejibaye (Bactris gasipaes H.B.K.) y $R$. johnstoni Keifer, en pacaya (Chamaedorea costaricana Oerst.), hasta la fecha (Ochoa et al. 1991a y 1994).

La identificación de los ácaros que se asocian con cultivos y plantas arvenses debe ser actualizada constantemente ya que, cada año, se presentan nuevas plantas atacadas por ácaros que en muchas ocasiones, habían sido identificados provenientes de otras plantas hospedantes. En algunas oportunidades se identifican ácaros que no estaban presentes en el país o que, por alguna razón, no habían sido detectados con anterioridad.

El objetivo de este trabajo es actualizar el inventario de las especies de ácaros fitófagos en Costa Rica para el período 2008-2012; asimismo, ofrecer datos de reconocimiento, hábitos y biología de varias de las especies consideradas actualmente como de mayor trascendencia económica.

\section{MATERIALES Y MÉTODOS}

La metodología seguida para procesar el material acarológico está descrita con detalle en el artículo de Aguilar y Murillo (2008). Una parte importante del material ha sido traída al Laboratorio por público interesado generalmente productores preocupados por los daños ocasionados por ácaros en sus diversas actividades. Otra, ha sido recolectada en diversas áreas del país por el personal adscrito al Laboratorio de Acarología.

Todo el material recolectado fue montado en solución Hoyer (Krantz y Walter 2009), colocado en una estufa a $40^{\circ} \mathrm{C}$ por al menos 3 días, o por el tiempo requerido según la muestra tratada. Luego se selló las láminas con barniz, poliuretano brillante ACE $1968924 \AA$ y se identificaron los especímenes con la ayuda de numerosas claves taxonómicas y los microscopios Olympus B 51 y Meiji MX 5310H, con contraste de fases.

Para la identificación de los ácaros de la familia Tetranychidae se emplearon las 
claves taxonómicas descritas en Aguilar y Murillo (2008): Pritchard y Baker (1955), Jeppson et al. (1975), Tuttle et al. (1976), Gutierrez (1985), además de Baker y Tuttle (1994) y las descripciones incluidas en Ochoa et al. (1991a y 1994).

En el caso de ácaros de la familia Tenuipalpidae, se emplearon las claves de Pritchard y Baker (1958), Ochoa y Salas (1989), Mesa et al. (2009) y Beard et al. (2012) y las descripciones encontradas en Ochoa et al. (1991a y 1994). Para identificar a los tarsonémidos se emplearon las claves de Lindquist (1986) y descripciones anotadas en Ochoa et al. (1991 a, b, 1994).

Para la familia Eriophyidae se empleó en su identificación las claves localizadas en algunas publicaciones (Jeppson et al. 1975, Keifer et al. 1982, Amrine y Stasny 1994) y las descripciones encontradas en Ochoa et al. (1991a, 1994). En el caso de la familia Phytoptidae, que está estrechamente relacionada con la Eriophyidae, se usaron las claves encontradas en Keifer (1965), Keifer et al. (1982) y las descripciones incluidas en Ochoa et al. (1991 a y 1994).

El trabajo se complementó con las consultas a varios especialistas, quienes verificaron las identificaciones efectuadas, cuando existía alguna duda al respecto. El material montado se encuentra depositado en la colección de Ácaros de Importancia Agrícola del Laboratorio de Acarología, Museo de Insectos, Escuela de Agronomía, Facultad de Ciencias Agroalimentarias, Universidad de Costa Rica.

\section{RESULTADOS Y DISCUSIÓN}

En esta recopilación se incluyen 65 registros asociados a 5 de las familias más importantes que poseen ácaros fitófagos: Tetranychidae, Tenuipalpidae, Tarsonemidae, Eriophyidae y Phytoptidae.

Cada país tiene sus propios problemas de ácaros en cultivos agrícolas y a veces la misma especie de ácaro se convierte en plaga según sea el país. En ocasiones se observa que una determinada especie que no es muy severa en un país, llega a ser radical en otro, e.g. Tetranychus cinnabarinus (Boisduval), que es una plaga muy seria en fresa en Turquía (Kazak y Kibritçi 2008), mientras que en Costa Rica lo es T. urticae. En el país, $T$. cinnabarinus no ha sido localizado en fresa, aunque si está presente en otros cultivos (Ochoa et al. 1991a y 1994, Aguilar y Murillo 2008). Dos importantes recopilaciones extensivas de ácaros de importancia fitoparásita son los trabajos de Carmona y Silva Dias (1996) en Portugal y de De Moraes y Flechtmann (2008) para Brasil. Los autores hacen una descripción de síntomas y daños de los principales ácaros fitófagos para ambos países, dándole énfasis a aquellos que son de limitación económica. Un número significativo de ellos no se han encontrado en Costa Rica, por lo que la situación en el país difiere notablemente de la realidad de Portugal y Brasil.

En Costa Rica se había realizado un trabajo de recopilación de ácaros fitófagos asociados con cultivos y otros tipos de plantas, con la adición de algunas especies que habían sido recolectadas en diversos países de América Central para la fecha en que fue publicada la Guía de Ácaros Fitófagos por Ochoa et al. (1991a), con una versión traducida al inglés y divulgada en 1994. Han pasado más de 20 años desde que ese trabajo fue publicado y muchas de las especies ahí consignadas todavía se presentan año con año al colonizar, nuevas plantas hospedantes. Asimismo, nuevas especies que no se identificaron durante ese período, se han presentado reiteradamente; algunas de ellas con gran impacto económico como es el caso de Steneotarsonemus spinki Smiley (Sanabria y Aguilar 2005, Hummel et al. 2009), que ha sido considerado un ácaro de difícil manejo en las zonas productoras de arroz del país, aún en la época actual.

Dada la importancia y necesidad de actualizar la identificación de ácaros fitófagos, Aguilar y Murillo publicaron un trabajo en donde recopilan las especies de ácaros fitófagos presentes en el país desde 2002 hasta 2008 (Aguilar y Murillo 2008). Con este trabajo se actualiza, nuevamente, la información, que comprende el período de 2008 hasta la primera mitad de 2012. Se hace imperecedero este tipo de estudios, ya que en los 
últimos 4 años se detectaron 65 nuevos registros de ácaros fitófagos en 51 especies de plantas pertenecientes a 29 familias (Cuadros 1, 2 y 3). La familia Tetranychidae aportó casi la mitad del material estudiado, seguida de Tarsonemidae con un 27\%; Tenuipalpidae no alcanzó el 14\%, Eriophyidae contribuyó con un poco más del $10 \%$ y por último, Phytoptidae, que solo fue recolectado en una planta hospedante, proporcionó un 1,5\% (Figura 1).

En el presente trabajo también se hará descripciones de síntomas en plantas, causados por algunos ácaros, ya que no se tiene en la mayoría de los casos, información pertinente sobre su diagnóstico, características de los ácaros y la relación establecida entre ellos y su planta hospedante.

Cuadro 1. Ácaros de la familia Tetranychidae hallados e identificados para Costa Rica en el período 2008-2012 con sus plantas hospederas.

\begin{tabular}{|c|c|c|}
\hline Especie de ácaro & Hospedero & Familia \\
\hline Eotetranychus deleoni & Ipomoea sp. & Convolvulaceae \\
\hline \multirow[t]{4}{*}{ Eutetranychus banksi } & Acnistus arborescens L. (güitite) & Solanaceae \\
\hline & Bactris gasipaes H.B.K. (pejibaye) & Palmae \\
\hline & Ipomoea cairica (L.) Sweet (churristate) & Convolvulaceae \\
\hline & Sapium spp. & Euphorbiaceae \\
\hline Mononychellus planki & Teramnus uncinatus (L.) Sw. & Fabaceae \\
\hline Oligonychus peronis & Acacia mangium Willd. & Fabaceae \\
\hline Oligonychus pratensis & Saccharum officinarum L. (caña de azúcar) & Poaceae \\
\hline Oligonychus punicae & Callistemon citrinus (Curtis) Skeels (hisopo) & Myrtaceae \\
\hline Oligonychus ununguis & Cupressus sp. (ciprés) & Cupressaceae \\
\hline \multirow[t]{2}{*}{ Oligonychus yothersi } & Anacardium excelsum (Kunth) Skeels (espavel) & Anacardiaceae \\
\hline & Tetrapanax papyrifer (Hook.) K. Koch (aralia gigante) & Araliaceae \\
\hline Paraponychus corderoi & Vigna vexillata $(\mathrm{L}$.$) A. Rich$ & Fabaceae \\
\hline Tetranychus cinnabarinus & Anthurium sp. (anturio) & Araceae \\
\hline \multirow[t]{2}{*}{ Tetranychus ludeni } & Thunbergia alata Bojer ex Sims & Acanthaceae \\
\hline & Cucumis melo L. (melón) & Cucurbitaceae \\
\hline \multirow[t]{2}{*}{ Tetranychus mexicanus } & Bactris gasipaes H.B.K. & Arecaceae \\
\hline & Especie no identificada & Arecaceae \\
\hline \multirow[t]{12}{*}{ Tetranychus urticae } & Benincasa hispida (Thunb.) Cogn. & Cucurbitaceae \\
\hline & Brassica oleracea var., italica Plenck (brócoli) & Brassicaceae \\
\hline & Cucurbita maxima Duchesne ex Lam. (zapallo) & Cucurbitaceae \\
\hline & Europs sp. & Asteraceae \\
\hline & Gladiolus sp. (gladiola) & Iridaceae \\
\hline & Gerbera sp. (gerbera) & Asteraceae \\
\hline & Glechoma sp., var. Nepeta & Lamiaceae \\
\hline & Heliconia latispatha Benth. (heliconia) & Heliconiaceae \\
\hline & Lactuca sativa $\mathrm{L}$. (lechuga) & Asteraceae \\
\hline & Luffa cylindrica M. Roem (paste) & Cucurbitaceae \\
\hline & Solanum mammosum L. (pichichío) & Solanaceae \\
\hline & Sonchus oleraceus L. (lechuguilla, serraja, serrajilla) & Asteraceae \\
\hline Tetranychus sp. & Rytidostylis gracilis Hook., y Arn. & Cucurbitaceae \\
\hline Tetranychus sp. & Tectona grandis L.f. & Lamiaceae \\
\hline Tetranychus sp. & Vigna vexillata (L.) A. Rich & Fabaceae \\
\hline Tetranychus sp. (solo hembras) & Bocconia frutescens L. (guacamayo) & Papaveraceae \\
\hline
\end{tabular}


Cuadro 2. Ácaros de la familia Tenuipalpidae hallados e identificados para Costa Rica en el período 2008-2012 con sus plantas hospederas.

\begin{tabular}{lll}
\hline Especie de ácaro & Hospedero & Familia \\
\hline Brevipalpus californicus & $\begin{array}{l}\text { Ipomoea cairica } \text { (L.) Sweet } \\
\text { Tetrapanax papyrifer } \text { (Hook.) K. (aralia gigante) }\end{array}$ & $\begin{array}{l}\text { Convolvulaceae } \\
\text { Araliaceae }\end{array}$ \\
\hline Brevipalpus gliricidiae & Gliricidia sepium (Jacq.) Kunth ex. Walp. (madero negro) & Fabaceae \\
\hline Brevipalpus obovatus & Teramnus uncinatus (L.) Sw. & Fabaceae \\
& Thunbergia alata Bojer ex Sims & Acanthaceae \\
\hline Brevipalpus phoenicis & Acacia mangium Willd. & Fabaceae \\
& Asparagus L. (espárrago ornamental) & Asparagaceae \\
& Phoenix roebelenii O’Brien & Palmae \\
& Heliconia latispatha Benth. (heliconia) & Heliconiaceae \\
\hline
\end{tabular}

Cuadro 3. Ácaros de la familia Tarsonemidae y superfamilia Eriophyoidea hallados e identificados para Costa Rica en el período 2008-2012 con sus plantas hospederas.

\begin{tabular}{|c|c|c|}
\hline Especie de ácaro & Hospedero & Familia \\
\hline \multicolumn{3}{|l|}{ TARSONEMIDAE } \\
\hline \multirow[t]{2}{*}{ Phytonemus pallidus } & Hedera sp. Var. Hellix & Araliaceae \\
\hline & Solanum quitoense Lam. (naranjilla) & Solanaceae \\
\hline \multirow[t]{15}{*}{ Polyphagotarsonemus latus } & Antirrhinum majus L. (Snap Dragon) & Plantaginaceae \\
\hline & Begonia semperflorens Link y Otto (begonia) & Begoniaceae \\
\hline & Cucumis melo L. (melón) & Cucurbitaceae \\
\hline & Iresine difusa Humb., y Bonpl., ex Willd. & Amarantaceae \\
\hline & Jatropha curcas L. (tempate) & Euphorbiaceae \\
\hline & Mimulus hybridus Voss (Monkey flower) & Scrophulariaceae \\
\hline & Mirabilis jalapa $\mathrm{L}$. & Nyctaginaceae \\
\hline & Pentas lanceolata (Forssk.) Deflers & Rubiaceae \\
\hline & Persea americana Mill. (aguacate) & Lauraceae \\
\hline & Plumbago sp. & Plumbaginaceae \\
\hline & Psidium guajava (guayaba) & Myrtaceae \\
\hline & Secchium edule (Jacq.) Sw. (chayote) & Cucurbitaceae \\
\hline & Solanum betacearum Cav. (tomate de palo) & Solanaceae \\
\hline & Solanum muricatum Aiton (pepino dulce) & Solanaceae \\
\hline & Solanum nigrum L. (hierba mora) & Solanaceae \\
\hline Steneotarsonemus ananas & Ananas comosus (L.) (piña) & Bromeliaceae \\
\hline \multicolumn{3}{|c|}{ Super familia ERIOPHYOIDEA } \\
\hline \multicolumn{3}{|c|}{ ERIOPHYIDAE } \\
\hline Abacarus doctus & Saccharum officinarum L. (caña de azúcar) & Poaceae \\
\hline Calepitrimerus muesebecki & Persea americana Mill. (aguacate) & Lauraceae \\
\hline Eriophyidae (expuesto) & Sechium edule (Jacq.) Sw. (chayote) & Cucurbitaceae \\
\hline Eriophyidae (expuesto) & Paspalum fasciculatum Willd., ex Flüggé (gamalote) & Poaceae \\
\hline Eriophyidae (expuesto) & Cojoba Britton y Rose (lorito) & Fabaceae \\
\hline Eriophyidae (expuesto) & Lippia alba (Mill.) N.E. Br., ex Britton y P. Wilson (juanilama) & Verbenaceae \\
\hline Eriophyidae ( no expuesto) & Lantana camara L. (cinco negritos) & Verbenaceae \\
\hline \multicolumn{3}{|l|}{ PHYTOPTIDAE } \\
\hline Retracrus johnstoni & Heliconia latispatha (Benth.) (heliconia) & Heliconiaceae \\
\hline
\end{tabular}

Agronomía Costarricense 36(2): 11-28. ISSN:0377-9424 / 2012 


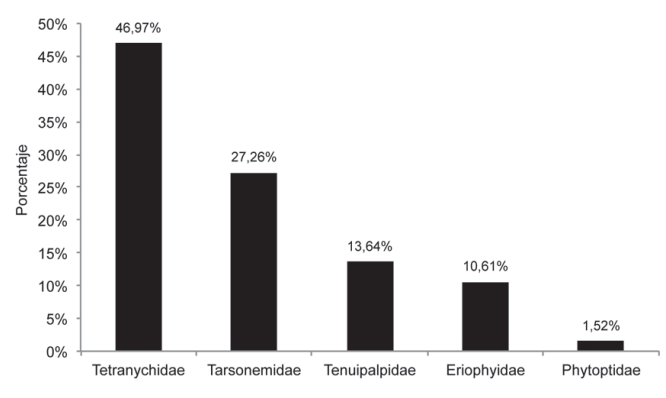

Fig. 1. Proporción de familias de ácaros fitófagos hallados en Costa Rica entre 2008 y 2012.

\section{RECONOCIMIENTO DE CAMPO}

\section{Familia Tetranychidae}

Los ácaros tetraníquidos informados en esta publicación fueron encontrados en diversas plantas, no todas ellas de importancia económica. Sin embargo, algunas especies fueron detectadas al causar daños económicos significativos que amerita una descripción de los mismos que puede ser de utilidad para los asesores en manejo de plagas, así como productores interesados en ampliar su conocimiento acerca de estos organismos. Con 12 nuevas plantas hospedantes, $T$. urticae se ubica detrás de $P$. latus en número de nuevos registros, para el período considerado.

\section{Oligonychus ununguis (Jacobi) en ciprés (Cupressus sp.)}

En Costa Rica, como sucede en numerosos países del mundo occidental, se utilizan los árboles de ciprés u otras coníferas para adornar casas, edificios, parques, etc., con motivo de la navidad. Estas plantaciones se encuentran normalmente en las partes altas de las provincias de San José, Cartago, Heredia y Alajuela, donde se dan condiciones climatológicas idóneas para el crecimiento de las coníferas. En marzo de 2012 se identificó, por primera vez en Costa Rica, al ácaro $O$. ununguis que causó daños de importancia económica en una de estas plantaciones, localizada en el distrito de Mata de Plátano, cantón de Guadalupe, en la provincia de San José, a $1400 \mathrm{msnm}$, aproximadamente. Esta arañita es conocida en los países de clima templado como "spruce spider mite", ya que fue localizada inicialmente atacando abetos en 1905 (Tuttle et al. 1974); por lo que es un ácaro habitual desde hace más de 100 años y asociado con numerosas especies de coníferas en, como se indicó, países europeos y norteamericanos.

El ácaro se alimenta en las ramas que se traduce en una decoloración de las hojas, las cuales se tornan de un color bronce claro que difiere mucho del verde natural de la conífera (Figura 2 A, B). Allí los ácaros forman una tela profusa que entrelaza a cada una de las hojas. Se observa además, una gran cantidad de exuvias y de los remanentes de los huevos (Figura $2 \mathrm{C}$ ); estos son esféricos y de alguna manera aplanados, con estipe dorsal; son de color anaranjado y pueden observarse depositados de forma desordenada e individualmente por todo el follaje, e igualmente sobre las ramas.

Las hembras tienen el propodosoma y patas de color anaranjado; el histerosoma se observa de un color marrón oscuro y en algunos especímenes se aprecia una coloración parda mucho más clara hacia el centro. Cuando las hembras son más maduras, todo el histerosoma es prácticamente negro y las manchas oculares son notablemente conspicuas.

El macho presenta la misma coloración de la hembra, con la combinación de colores ya descrita, se ubican por todas las áreas donde se localizan las hembras y los estadios inmóviles o quiescentes, llamados crisálidas.

Las larvas presentan un color marrón claro uniforme o anaranjado y las ninfas muestran el mismo patrón de las hembras. Todos los estadios se aprecian vagando por las ramas y hojas.

La decoloración se observa en cada una de las hojas escuamiformes, por lo que las ramas se aprecian con ese tono en su totalidad. Éstas pierden el color verde característico del ciprés $\mathrm{y}$ adquieren un color bronceado opaco uniforme que contrasta con el típico patrón de un árbol de Navidad (Figura 2 A y B). 


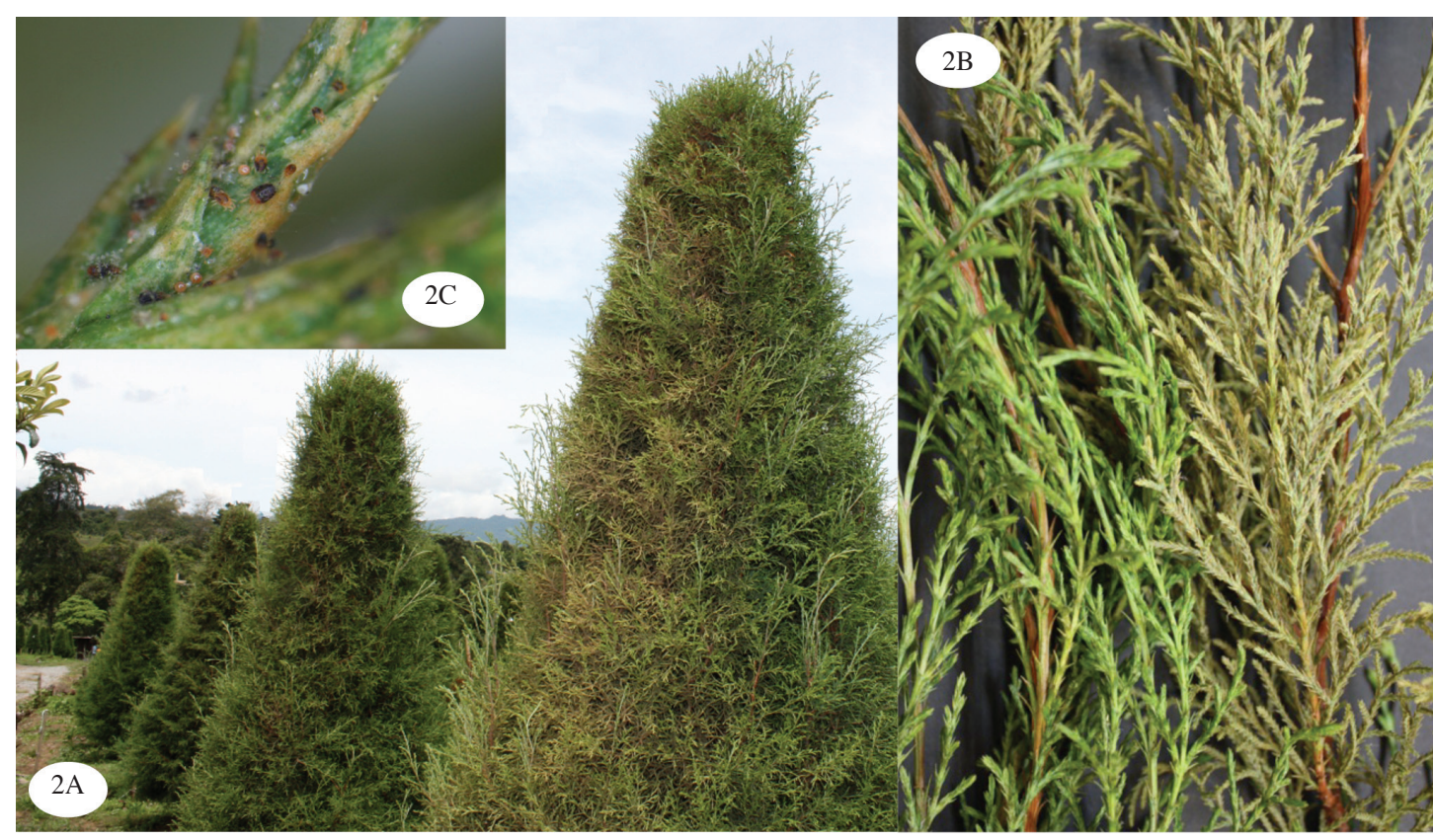

Fig. 2. A. Árboles de ciprés afectados por Oligonychus ununguis en una plantación comercial. B. Detalle del daño producido por el ácaro en las ramas. C. O. ununguis alimentándose en una rama de ciprés.

Aparte de la presencia de mudas, huevos y estadios activos sobre las ramillas, no se aprecian en éstas cambios en coloración.

\section{Otros daños provocados por tetraníquidos}

En Gladiolus sp., T. urticae se localiza en el envés de las hojas, donde agrupa altas poblaciones que se alimentan con avidez, lo que produce una serie de punteaduras amarillentas o blanquecinas que llegan a unirse y que provee, como consecuencia, una pérdida de coloración en las hojas de manera uniforme (Figura 3 A y B). Las formas móviles, tanto adultos como inmaduros, son observadas a lo largo de la hoja (Figura $3 \mathrm{C}$ ).

Tetranychus cinnabarinus es otra arañita roja que por primera vez en el país se observó asociada con Anthurium sp. Como es común en otras especies de tetraníquidos, especialmente el género Tetranychus, presenta colonias que se localizan en el envés de las hojas (4 C), donde se observó una coloración blanquecina, casi plateada entre las venas del follaje, mientras que éstas se conservan de color verde (Figura 4 A). Observadas por el haz, las hojas tienen parches cloróticos en las áreas que coinciden con los grupos de poblaciones de la arañita en el envés (Figura 4 B).

Tetranychus urticae fue visto, por primera vez en el país, asociado con Brassica oleracea var., italica Plenck, brócoli, encontrándose sus poblaciones, como es usual en esta especie, en el envés de las hojas. Allí forman grandes colonias entre las venas, en donde producen una tela muy profusa que les sirve como protección de las condiciones ambientales y al ataque de depredadores. Los síntomas observados por el envés son similares a los producidos en otras plantas hospedantes: pérdida de coloración del sustrato (Figura $5 \mathrm{~A}$ ). Esta especie de arañita también fue encontrada en plántulas de Tectona grandis L.f., en las que se manifiesta una clorosis generalizada en las hojas (Figura 5 B). Asimismo, en Heliconia latispatha 


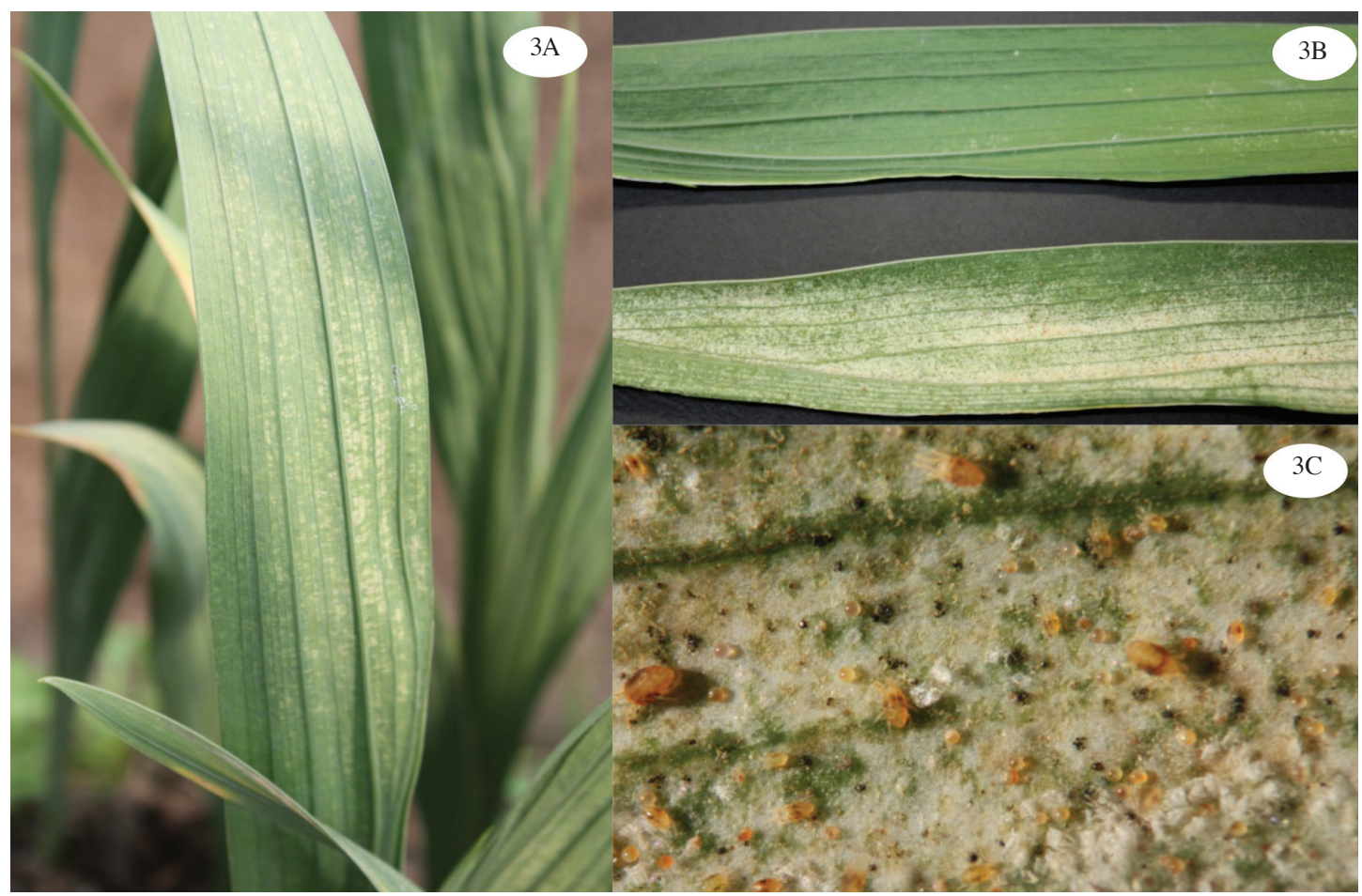

Fig. 3. A y B. Daño provocado por Tetranychus urticae en Gladiolus sp. C. Adultos, inmaduros y exuvias del ácaro en envés del follaje.

Benth., se observan los propios síntomas producidos por T. urticae en otras plantas, iniciándose en la base de las hojas y extendiéndose hacia el ápice; también es común advertir, en este hospedante, un incremento en la clorosis hacia los bordes del follaje (Figura $5 \mathrm{C}$ ).

Los síntomas provocados por las diversas especies del género Oligonychus, difieren notablemente de aquellos producidos por el género Tetranychus. Por lo general, los ácaros se localizan en el haz de las hojas y se producen tonalidades bronceadas en las mismas, como es el caso de Callistemon citrinus (Curtis) Skeels, atacada por $O$. punicae (Figura 6 A) y Tetrapanax papyrifer (Hook.) K. Koch, por O. yothersi (Figura $6 \mathrm{~B}$ ). Con los ataques producidos por estas 2 especies, el follaje de la planta hospedante se observa cobrizo por toda la lámina y si se hace una inspección minuciosa, se pueden apreciar los diversos estadios del ácaro diseminados por ella, con una gran cantidad de mudas y polvo acumulado, ya que la tela generada por el ácaro, aunque no tan profusa como en otras especies de arañitas, sirve de barrera junto con el polvo, permitiéndole a los ácaros establecer refugios que le servirán como protección de las condiciones bióticas y abióticas. 


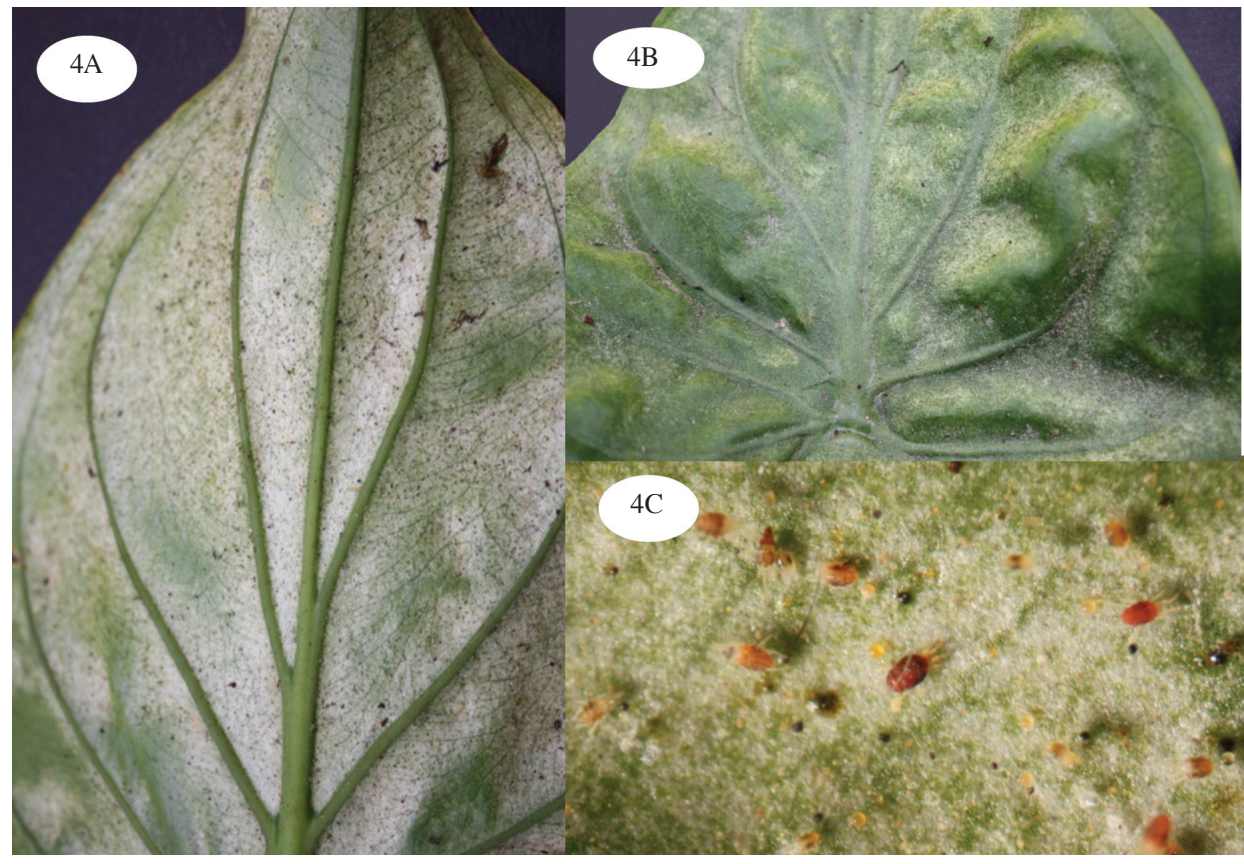

Fig. 4. $\quad$ A y B. Daño producido por Tetranychus cinnabarinus en follaje de Anthurium sp., envés y haz, respectivamente. C. Hembras, inmaduros y huevos de T. cinnabarinus en envés del follaje.

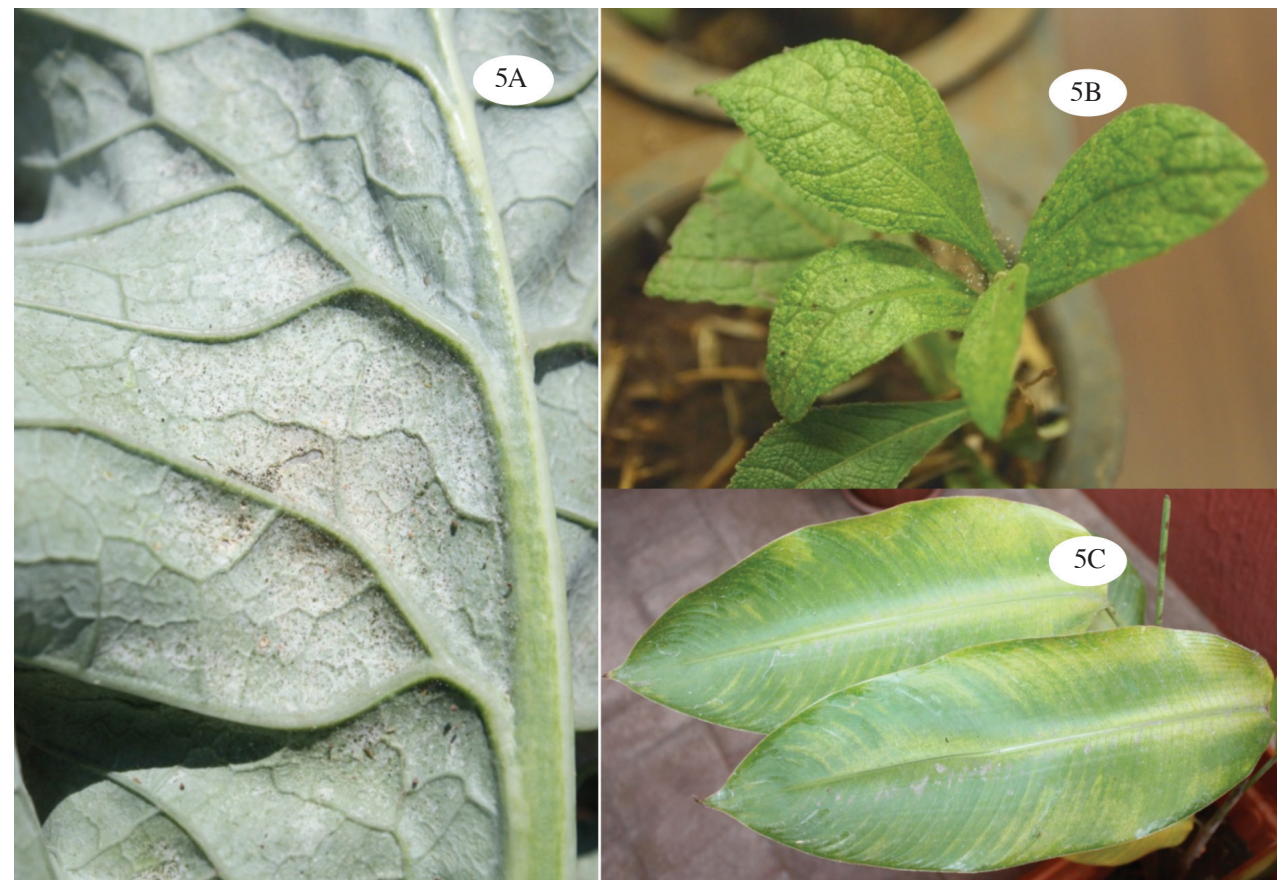

Fig. 5. A. Síntomas asociados a T. urticae en envés de hojas de Brassica oleracea var., italica. B. Daño en follaje y tela producida por T. urticae en plántula de Tectona grandis. C. Clorosis provocada por T. urticae en follaje de Heliconia latispatha. 


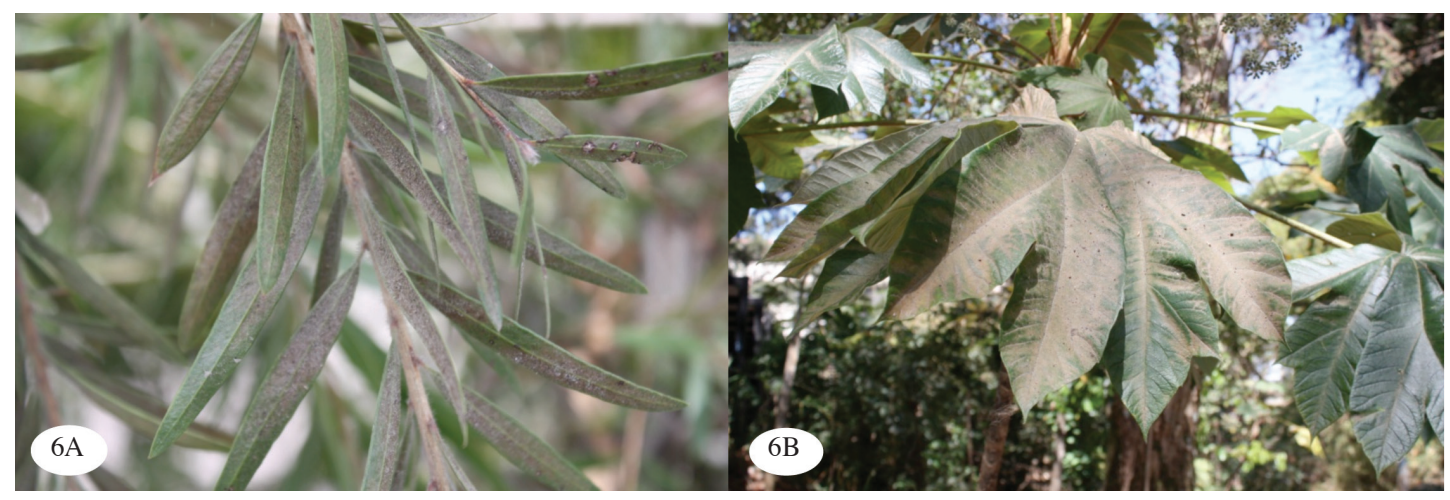

Fig. 6. A. Bronceado del follaje de Callistemon citrini producido por Oligonychus punicae. B. Hojas de Tetrapanax papyrifer atacadas por $O$. yothersi.

\section{Familia Tenuipalpidae}

\section{Brevipalpus phoenicis (Geijskes) en Phoenix roebelenii $\mathrm{O}^{\prime}$ Brien}

Esta especie de ácaro es muy conocida a nivel mundial, dado que es cosmopolita, aparte de que se asocia a una miríada de cultivos de importancia económica como cítricos, plantas ornamentales, frutales y muchas más (Ochoa et al. 1991a y 1994). Es la especie que se relaciona con la transmisión de la leprosis de los cítricos; rabdovirus que ha provocado grandes problemas en plantaciones de cítricos en Suramérica y Panamá (Childers et al. 2003, Childers y Rodrigues 2011). En Costa Rica, la especie es conocida desde hace muchos años, se asocia con más de 116 plantas hospedantes y se reconoce como el ácaro plano más común (Ochoa et al. 1991a y 1994, Aguilar y Murillo 2008).

Se recibió material de una plantación comercial de plantas ornamentales localizada en Turrialba, provincia de Cartago. El daño provocado en la palma $P$. roebelenii por $B$. phoenicis, se observó en hojas (frondas) bajeras, produciéndose una clorosis en los foliolos, la que empieza en los más cercanos a la base y se extiende hacia el ápice. Cuando el daño es muy severo, los foliolos tienden a necrosarse. En muchas de las hojas se manifiesta una coloración cobriza o bronceada en el envés de las mismas (Figura 7 A). Al observarse al estereoscopio, los ácaros se ven agrupados en el envés, a lo largo de los foliolos. Además, se aprecian formas móviles, crisálidas (estado inactivo), a todo lo largo de ellos. Se aprecian secciones blanquecinas en abundancia, que corresponden a las exuvias del ácaro.

Los huevos son depositados individualmente o en conjunto, sobre o debajo de las exuvias, como medida de protección. Se han observado grupos que van de 5 hasta 20 huevos. Acumulaciones de huevos también se han visto depositadas en la base de los foliolos y en los bordes de los mismos. Después de un ataque muy severo, las hojas se necrosan completamente y el daño más severo se observa en los ápices de cada foliolo. 


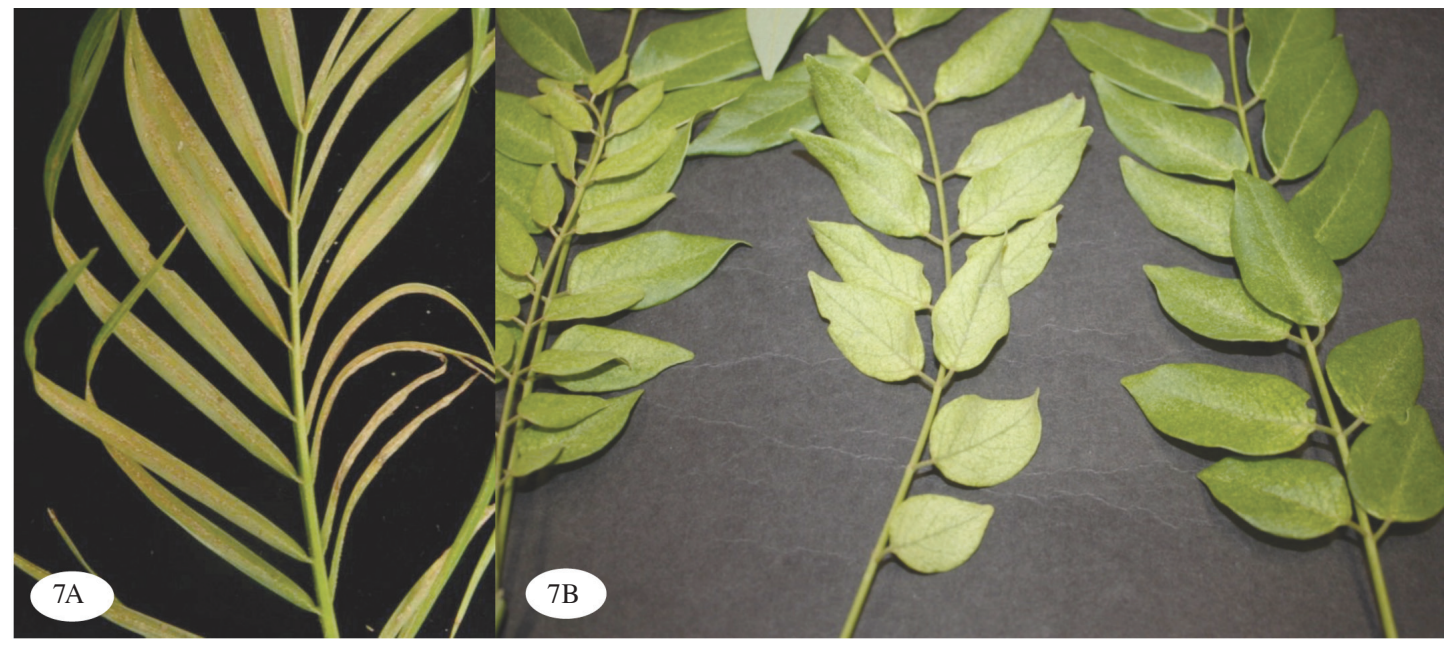

Fig. 7. A. Daño producido por B. phoenicis en foliolos de Phoenix roebelinii. B. Clorosis provocada por Brevipalpus gliricidiae en hojas de Gliricidia sepium.

\section{Otros daños provocados por tenuipálpidos}

Los daños producidos por ácaros del género Brevipalpus pueden variar, según la planta hospedante. Por ejemplo, B. gliricidiae DeLeon, encontrado por primera vez en Costa Rica en madero negro, Gliricidia sepium Kunth ex Steud., produce una clorosis generalizada de los foliolos, lo que luego origina defoliación en los árboles afectados por este ácaro plano (Figura 7 B).

\section{Familia Tarsonemidae}

\section{Polyphagotarsonemus latus (Banks) en Jatropha curcas L.}

El ácaro blanco, Polyphagotarsonemus latus (Banks), es una especie que se ha encontrado relacionada con nuevas plantas hospedantes, principalmente en ornamentales y arvenses. En el período de 2008 a 2012, 15 nuevas plantas han sido registradas para el ácaro blanco.

Aguilar y Murillo (2008) mencionan al ácaro blanco asociado con el tempate (Jatropha curcas L.), planta con potencial para fuente de biodiesel. Sin embargo, no hacen una descripción de los daños, notablemente severos, que han puesto en riesgo el desarrollo de las investigaciones sobre este posible combustible no fósil.

Material de tempate recolectado en la Estación Experimental Fabio Baudrit, de la Universidad de Costa Rica, en julio de 2009, presentaba poblaciones muy altas de $P$. latus, especialmente de huevos que eran observados por todo el envés de los brotes. Allí, muchas de las plantas mostraban el follaje corrugado, típico del ataque de este ácaro (Figura $8 \mathrm{~A}$ ). El envés de los brotes exponía un resquebrajamiento (Figura $8 \mathrm{~B}$ ). El ataque ocurre desde que los brotes son muy pequeños impidiendo el desarrollo foliar.

Las hojas pequeñas adquieren una coloración marrón y cuando están desarrolladas, se ven corrugadas y mucho más pequeñas que las normales. El resquebrajamiento se observa también en los tallos tiernos y pecíolos. Las hojas más desarrolladas de las plantas se ven corrugadas por el haz y bronceadas por el envés. En hojas con muchos huevos en el envés se observan formas móviles y los huevos también son apreciados por el haz, pero en poblaciones más bajas. Son puestos sobre el sustrato, sin ninguna distribución en particular. Los machos vagan por la superficie del sustrato cargando las ninfas que posteriormente darán origen a las hembras (Figura 8C). 


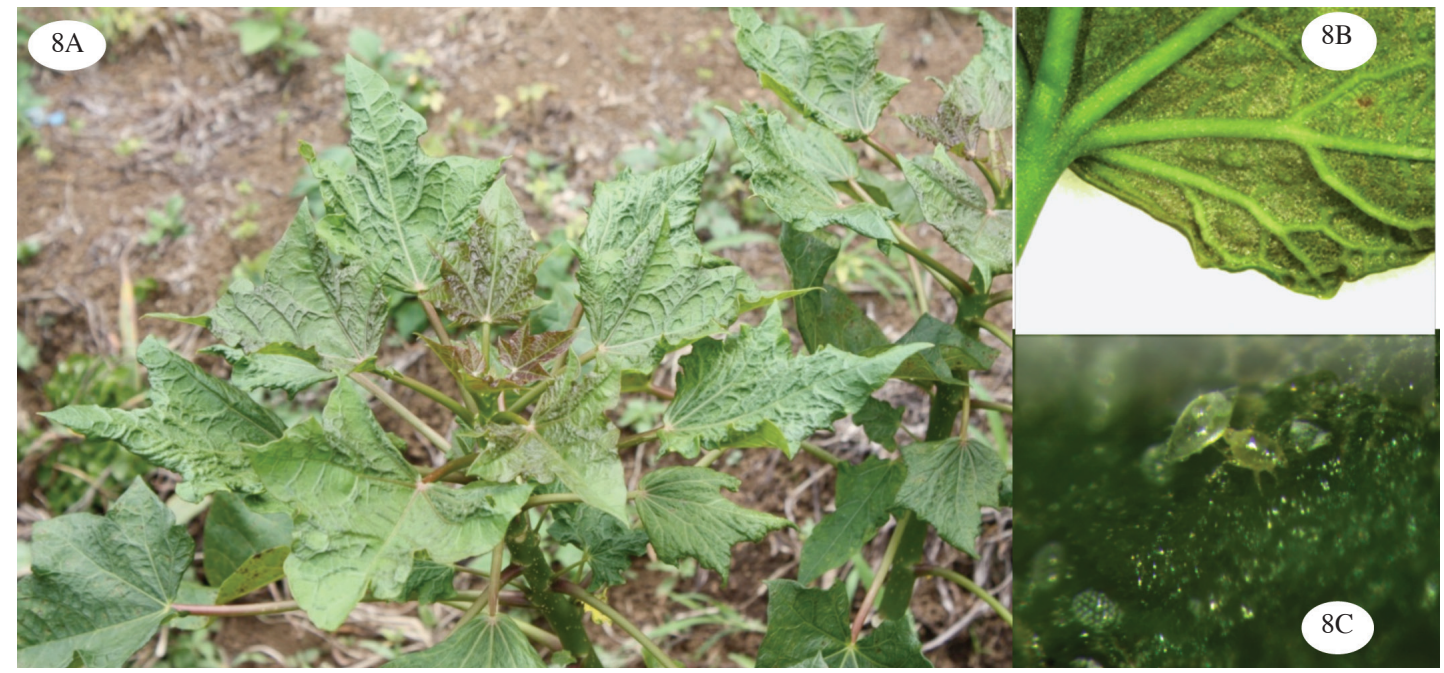

Fig. 8. Daño inducido por Polyphagotarsonemus latus en Jatropha curcas. A. Planta. B. Detalle en hoja. C. Macho acarreando ninfa cerca de un huevo.

\section{Polyphagotarsonemus latus (Banks) en Phaseolus vulgaris $\mathrm{L}$.}

Polyphagotarsonemus latus ha sido observado, en el país, asociado al follaje y frutos de muchas plantas hospedantes (Ochoa et al. 1991a y 1994, Aguilar y Murillo 2008). Si bien es cierto, $P$. latus ya había sido mencionado asociado con el frijol común en el pasado (Ochoa et al. 1991a y 1994), esta es la primera vez que se observa en Costa Rica un daño severo en las vainas de esta importante fabácea.

Cuando hay ataque, las vainicas en desarrollo pueden sufrir deformaciones, mostrándose arqueadas. Se aprecia una mancha color marrón a todo lo largo de la vaina; en algunas de ellas, por ambos lados y, en otras, por solo uno. Al observar las vainas al estereoscopio, se aprecian diferentes tonalidades de marrón: unas muy oscuras, casi negras, mientras que otras son de color más claro (Figura 9 A). En algunas de esas lesiones se aprecian grandes cantidades de ácaros, de todos los estadios, así como huevos. En otras, se observa el corion de los huevos adherido fuertemente al sustrato.
La lesión en las vainas tiende a ser irregular y muy severa. Debido a la numerosa cantidad de restos de huevos, es posible que el ataque haya ocurrido temprano en el desarrollo de las vainas. Cuando los daños alcanzan un grado alto de severidad, se tornan en lesiones oscuras y hundidas (Figura 9 B). Los ácaros también pueden ser observados en el follaje ya que provocan un bronceado en el envés, donde es posible observar todos los estadios del ácaro.

\section{Otros daños provocados por tarsonémidos}

Los síntomas producidos por P. latus y otros ácaros de la familia Tarsonemidae, son muy similares, ya que atacan los brotes de la planta hospedera, e inducen a deformación de los mismos y se observan acucharamientos y distorsión de la lámina, como puede apreciarse en Pentas lanceolata (Forssk.) Deflers e Iresine difusa Humb., y Bonpl. ex Willd. (Figura 9 C y D). En muchas ocasiones, el envés de los brotes se torna de un color bronceado uniforme, como se distingue en los de hierba mora (Solanum nigrum L.) (Figura 9 E). 


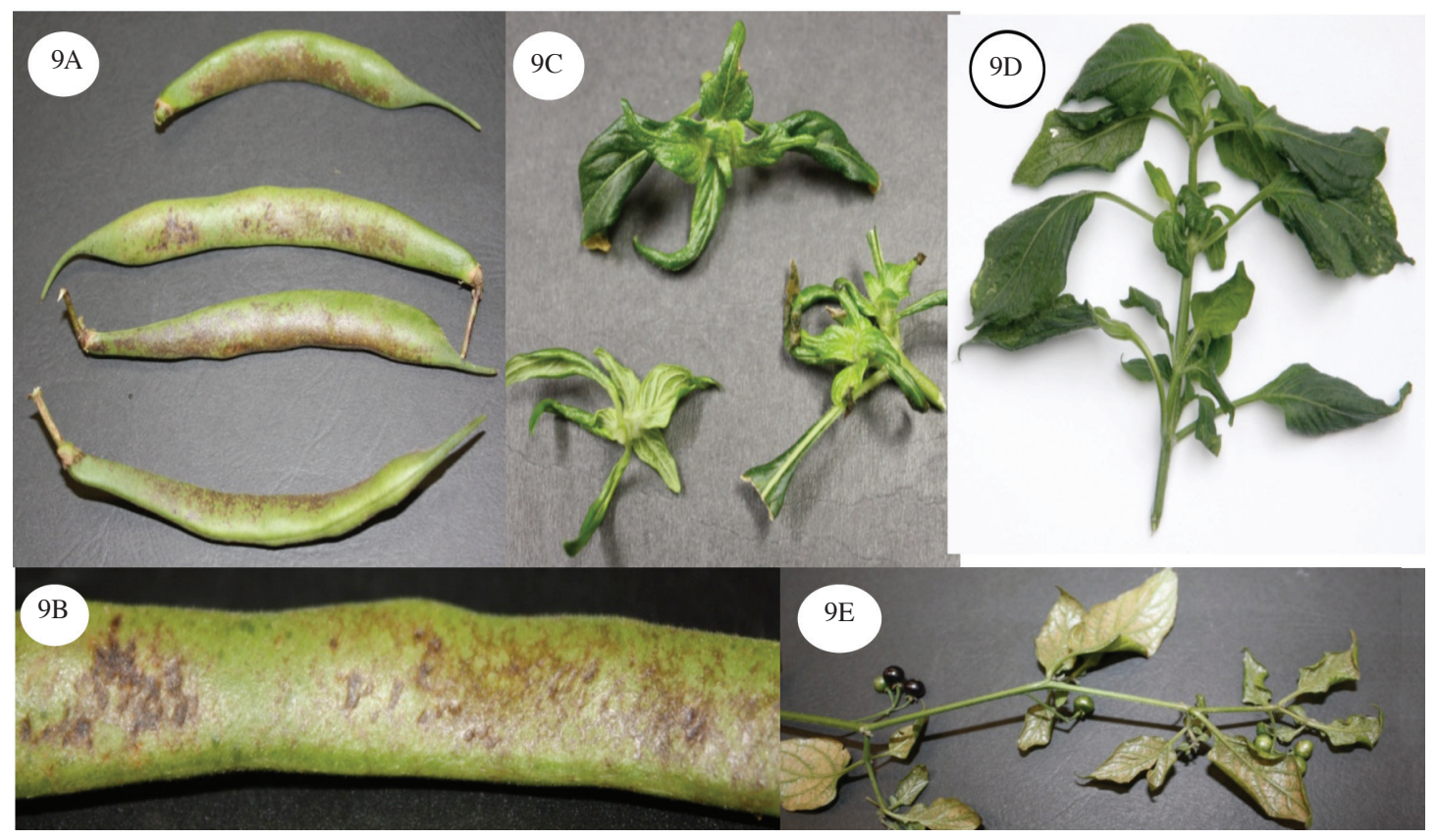

Fig. 9. Síntomas producidos por P. latus en diversos hospederos: A y B. Vaina de Phaseolus vulgaris. C. Pentas lanceolata. D. Iresine difusa. E. Solanum nigrum.

\section{Familia Phytoptidae}

\section{Retracrus johnstoni Keifer en Heliconia latispatha Benth}

La información existente sobre el género Retracrus es escasa y al hacer una revisión profusa de la literatura disponible, se encuentra que este género se ha observado asociado solamente con palmas; el $R$. elaeis con palma aceitera y pejibaye y $R$. johnstoni con pacaya, en Costa Rica (Ochoa et al. 1991a, 1994). Sin embargo esta última especie ha sido recolectada de la planta ornamental $H$. latispatha que pertenece a la familia Heliconiaceae. Es la primera vez que una especie del género Retracrus se reproduce en un hospedero que no pertenece a la familia Arecaceae. Se debe dilucidar si se trata de la misma especie que se asocia con Chamaedorea costaricana Oerst., o bien, si se trata de una especie críptica.
Los síntomas en la heliconia son bastante severos y conspicuos. Se aprecian colonias muy numerosas en el envés de las hojas, sobre una lesión muy desarrollada de color bronce. Los ácaros se observan cubiertos por una capa cerosa, de la misma manera que $R$. johnstoni en pacaya.

En hojas con un ataque muy severo se aprecia una mancha de color marrón uniforme, especialmente hacia la base de las mismas. Esta lesión se distingue también en los bordes de la lámina, que se extiende hacia la parte distal. Igualmente se observan lesiones a lo largo de la vena central de la hoja y en algunas se aprecian pequeñas manchas a los lados de las venas secundarias, todas ellas con poblaciones de ácaros (Figura $10 \mathrm{~B}$ ).

Por el haz de la hoja se distingue una clorosis en las áreas que coinciden con las poblaciones ubicadas en el envés. La lámina puede llegar a estar completamente infestada por el ácaro, por 


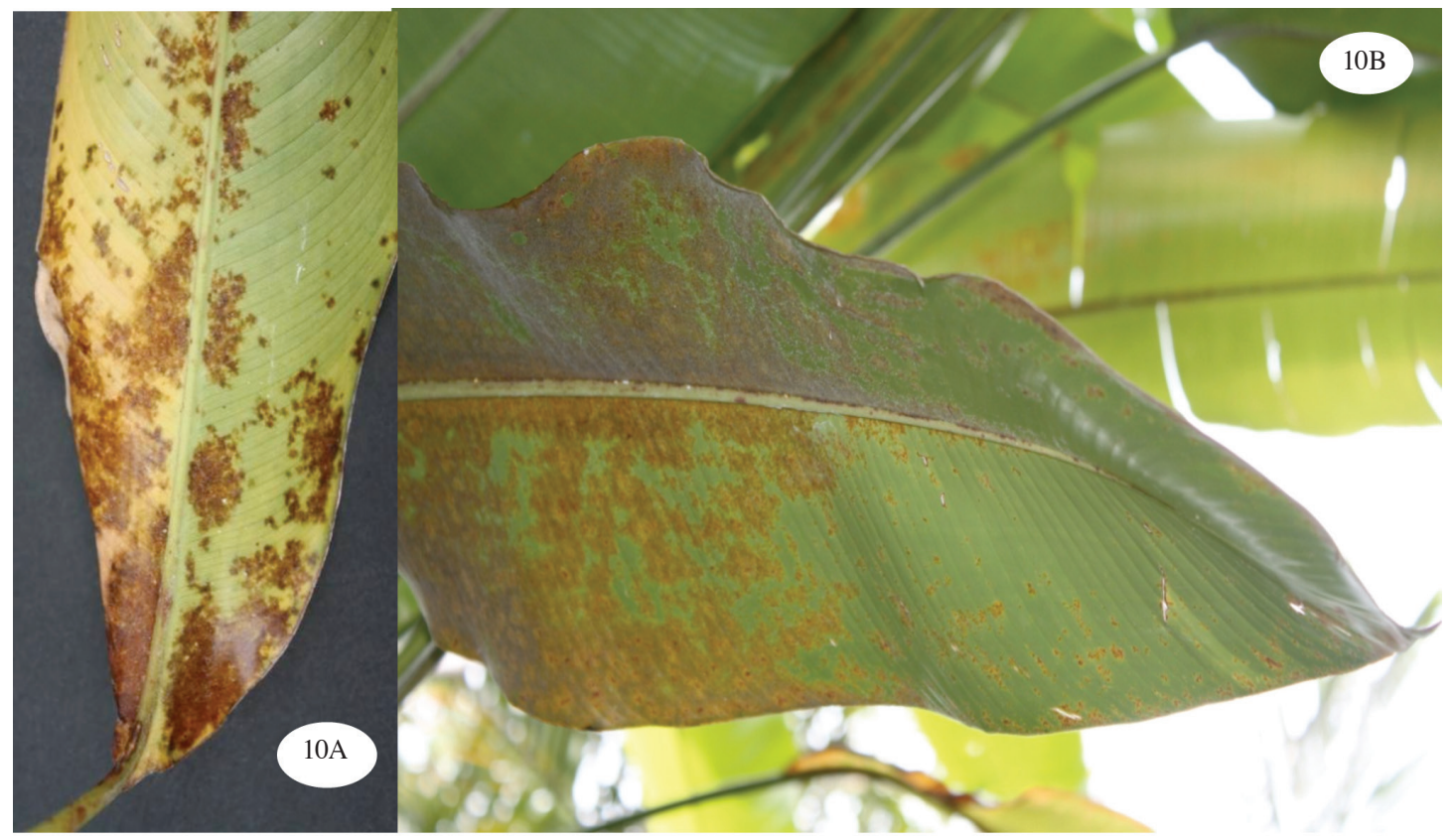

Fig. 10. Síntomas inducidos por Retracrus johnstoni en Heliconia latispatha: A. Planta. B. Detalle en hoja.

lo que el color verde natural de la hoja se torna marrón (Figura 10 A).

Al estudiar las plantas atacadas por el ácaro in situ, se pueden ver pequeñas manchas necróticas en el envés de las hojas, tanto en la lámina como en la vena central, con altas poblaciones del ácaro, así como de mudas. Estas pequeñas manchas pueden ser también observadas en los bordes de las hojas que tienden a doblarse levemente. En ocasiones se percibe un tenue halo clorótico circundando la mancha necrótica. Estas manchas son irregulares y el halo clorótico se vuelve más perceptible con el tiempo (Figura $10 \mathrm{~B}$ ).

Se puede observar una clorosis generalizada en las hojas con lesiones en algunas áreas de las láminas y de diferente tamaño. En la planta pueden observarse hojas totalmente verdes, en cualquier parte de la misma, pero principalmente en el área superior. A contraluz, el amarillamiento de la lámina es muy evidente y notable. No se observaron ácaros en el haz de las hojas.

También se aprecian lesiones pequeñas a lo largo de la vena media y dispersas por la lámina. Dichas manchas están pobladas de gran cantidad de mudas y probablemente, de excrecencias cerosas producidas por los ácaros, de tal manera que las densidades de estos pequeños arácnidos per se, son bajas, en comparación a la enorme cantidad de mudas y desechos.

Al observar los ácaros al estereoscopio, éstos lucen muy similares, como se mencionó atrás, a $R$. johnstoni en pacaya y como otros del mismo género, se considera que sus plantas hospedantes son palmas de la familia Arecaceae. 


\section{Familia Eriophyidae}

\section{Abacarus doctus Navia y Flechtmann en Saccharum officinarum $\mathrm{L}$.}

Esta especie, nueva para la ciencia y descrita por Navia y Flechtmann (Navia et al. 2011), es el primer registro de un ácaro asociado con caña de azúcar en Costa Rica. De otras latitudes se conocen varias especies de ácaros de la familia Eriophyidae relacionadas con este cultivo (Ozman et al. 2006). Según información obtenida de los funcionarios del Servicio Fitosanitario del Estado, el ácaro se encuentra distribuido por todo el país, principalmente en las plantaciones de caña de la provincia de Puntarenas y en San Isidro de El General, San José (C. Sanabria. 2010. Aeropuerto Juan Santamaría. Comunicación personal). Navia et al. (2011) describen los síntomas asociados a altas infestaciones del ácaro como manchas rojizas o bronceadas dispersas al azar en las superficies internas de las hojas, que pueden extenderse para cubrir casi completamente la vaina de la hoja. A la distancia, tales síntomas de daño podrían ser confundidos con los causados por las herrumbres fungosas, que están comúnmente asociadas con caña de azúcar (Figura $11 \mathrm{~A}$ y C). Con la ayuda de una lupa de $10 \mathrm{X}$ o más, se pueden observar los diferentes estadios del ácaro vagando a lo largo de los foliolos por el envés de las hojas (Figura $11 \mathrm{~B}$ ).

Algunas de las variedades más susceptibles al ataque del ácaro y que presentan una manifestación de síntomas más evidentes son SP-71-5574, RB-73-9735, SP-79-2233, CP-892143, MEX 57-473, entre otras de diversos orígenes. Es importante anotar que la susceptibilidad al ataque de este ácaro de las variedades ha sido observada en todas las zonas productoras de caña de azúcar en el país (J.D. Salazar. 2012. DIECA. Comunicación personal).

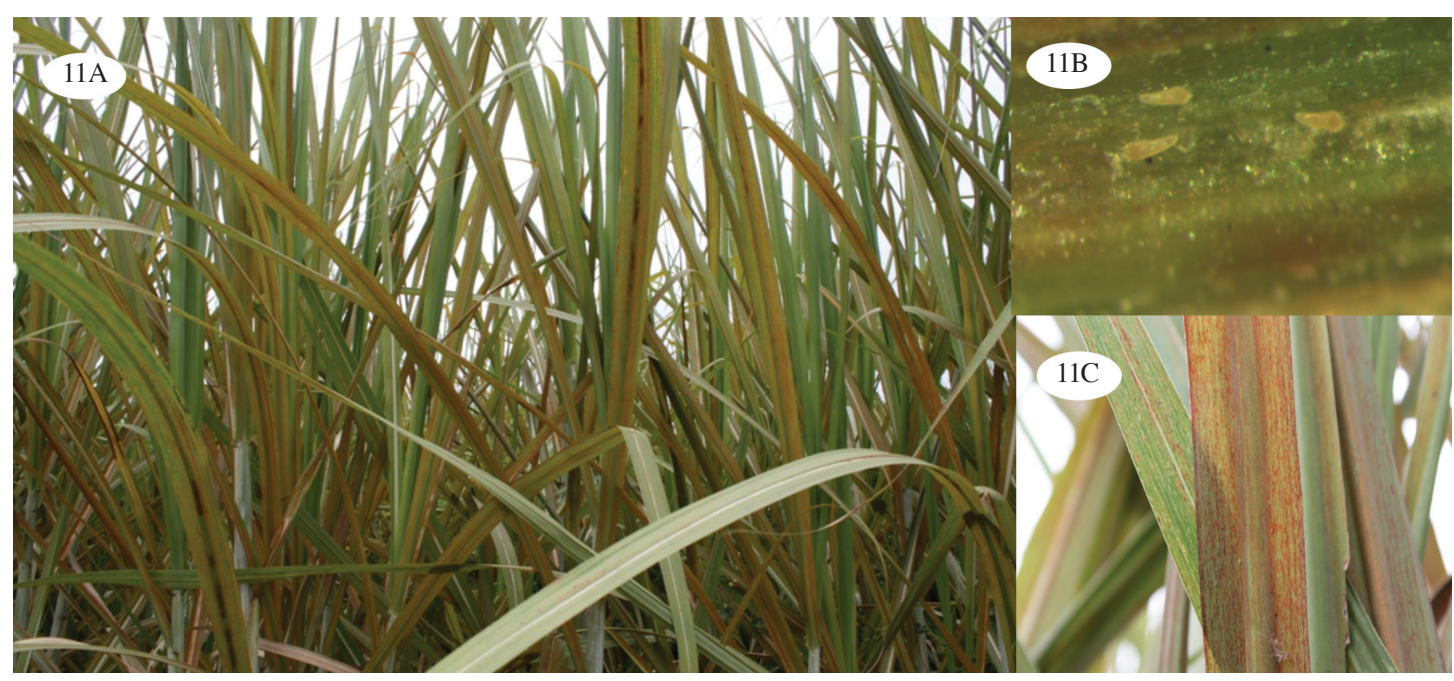

Fig. 11. A. Daños producido por Abacarus doctus en plantación de Saccharum officinarum. B. Ácaros en follaje. C. Detalle del síntoma en foliolo. 


\section{AGRADECIMIENTOS}

A las Dras. Mónica Blanco y Adriana Murillo, por la revisión del manuscrito y valiosas sugerencias aportadas.

\section{LITERATURA CITADA}

AGUILAR H., MURILlO P. 2008. Nuevos hospederos y registros de ácaros fitófagos para Costa Rica: período 2002-2008. Agronomía Costarricense 32(2):7-28.

AMRINE J.W. Jr., STASNY T.A. 1994. Catalog of the Eriophyoidea (Acarina: Prostigmata) of the World. Indira Publishing House, West Bloomfield, Michigan, USA. 798 p.

BAKER E.W., TUTTLE D.M. 1994. A guide to the spider mites (Tetranychidae) of the United States. Indira Publishing House, West Bloomfield, Michigan. 347 p.

BEARD J.J., OCHOA R., BAUCHAN G.R., TRICE M.D., REDFORD A.J., WALTERS T.W., MITTER C. 2012. Flat Mites of the World - Part I Raoiella and Brevipalpus. Identification Technology Program, CPHST, PPQ, APHIS, USDA; Fort Collins, CO $(21 / 06 / 12)$.

CARMONA M.M., SILVA DIAS J.C. 1996. Fundamentos de Acarologia Agrícola. Fund. Calouste Gulbenkian, Lisboa. 423 p.

CARRILLO D., NAVIA D., FERRAGUT F., PEÑA J.E. 2011. First report of Raoiella indica (Acari: Tenuipalpidae) in Colombia. Florida Entomologist 94(2):370-371.

CHILDERS C.C., FRENCH J.V., RODRIGUES J.C.V. 2003. Brevipalpus californicus, B. obovatus, B. phoenicis, and $B$. lewisi (Acari: Tenuipalpidae): a review of their biology, feeding injury and economic importance. Experimental and Applied Acarology 30:5-28.

CHILDERS C.C., RODRIGUES J.C.V. 2011. An overview of Brevipalpus mites (Acari: Tenuipalpidae) and the plant viruses they transmit. Zoosymposia 6:180-192.

CZAJKOWSKA B., PUCHALSKA E. 2006. European larch (Larix decidua) and sweet chestnut (Castanea sativa) as host plants of spruce spider mites (Oligonychus ununguis Jacobi). Biological Lett. 43(2):307-313.

DANIELSSON M. 2011. Chemical defence in Norway Spruce. Tesis de doctorado. Royal Institute of Technology, Estocolmo. 63 p.

DE MORAES G.J., FLECHTMAN C.H.W. 2008. Manual de Acarologia; acarologia básica e ácaros de plantas cultivadas no Brasil. Holos, Editora. Riberao Preto, SP. 288 p.

FENILLI R., FLECHTMANN C.H.W. 1990. Ácaros do pinheiro-do-Paraná em Lages, Santa Catarina. Anais da ESALQ, Piracicaba 47(1):243-250.
FLORES-GALANO G., MONTOYA A., RODRÍGUEZ H. 2010. Biología de Raoiella indica Hirst (Acari: Tenuipalpidae) sobre Areca catechu L. Rev. Protección Veg. 25(1):11-16

GUTIERREZ J. 1985. Systematics, pp. 75-90. In: W. Helle and M.W. Sabelis (eds.). World Crop Pests: Spider Mites Their Biology, Natural Enemies and Control, Elsevier No. 1A. Chapter 1.1 Anatomy, Phylogeny and Systematics 1.1.4. Amsterdam.

GUTIERREZ J., SCHICHA E. 1983. The spider mite family Tetranychidae (Acari) in New South Wales. International Journal of Acarology 9(3):99-115.

HALLIDAY R.B. 2010. Taxonomic confusion surrounding mite pests of sugarcane and rice (Acari: Eriophyidae). Systematic and Applied Acarology 35:257-262.

HUMMEL N.A., CASTRO B.A., McDONALD E.M., PELLERANO M.A., OCHOA R. 2009. The panicle rice mite, Steneotarsonemus spinki Smiley, a re-discovered pest of rice in the United States. Crop Protection 28:547-560.

JEPPSON L.R., KEIFER H.H., BAKER E.W. 1975. Mites injurious to economic plants. University of California Press, Berkeley. 648 p.

KANE E.C., OCHOA R. 2010. Identificación y determinación del ácaro rojo de las palmas Raoiella indica Hirst (Acari: Tenuipalpidae). Boletín Programa Nacional Sectorial de Producción Agrícola Bajo Ambientes Protegidos (Costa Rica) 4(24):10-14.

KANE E.C., OCHOA R., MATHURIN G., ERBE E.F., BEARD J.J. 2012. Raoiella indica (Acari: Tenuipalpidae): an exploding mite pest in the neotropics. Experimental and Applied Acarology 57:215-225.

KAZAK C., KIBRITÇI C. 2008. Population parameters of Tetranychus cinnabarinus Boisduval (Prostigmata: Tetranychidae) on eight strawberry cultivars. Turk. J. Agric. For. 32:19-27.

KEIFER H.H. 1965. Eriophyid Studies B-16, Bureau of Entomology, California Department of Agriculture, p. $7-8$.

KEIFER H.H., BAKER E.W., KONO T., DELFINADO M., STYER W.E. 1982. An illustrated guide to plant abnormalities caused by eriophyid mites in North America. USDA. Handbook No. 573. 178 p.

KRANTZ G.W., WALTER D.E. 2009. A manual of acarology. Texas Tech University Press, $3^{\text {era }}$ ed. 807 p.

LINDQUIST E.E. 1986. The world genera of Tarsonemidae (Acari: Heterostigmata): a morphological, phylogenetic, and systematic revision, with a reclassification of family-group taxa in the Heterostigmata. Memoirs of the Entomological Society of Canada No ${ }^{\circ}$. 136. S.B. Ewen, ed, Ottawa. $517 \mathrm{pp}$.

MESA N.C., OCHOA R., WELBOURN W.C., EVANS G.A., DE MORAES G.J. 2009. A catalog of the 
Tenuipalpidae (Acari) of the World with a key to genera. Zootaxa 2098:1-185.

NATURAL RESOURCES CANADA. 2011. Spruce spider mite. In: http://tidcf.nrcan.gc.ca/insects/ factsheet/136 (04/04/12).

NAVIA D., FLECHTMANN C.H.W., LINDQUIST E.E., AGUILAR H. 2011. A new species of Abacarus (Acari: Prostigmata: Eriophyidae) damagaing sugarcane, Saccharum officinarum L., from Costa Rica-the first eriophyid mite described with a tibial seta on leg II." Zootaxa 3025: 51-58.

OCHOA R., AGUILAR H., VARGAS C. 1991a. Ácaros fitófagos de América Central. CATIE. Turrialba, Costa Rica. 251 p.

OCHOA R., AGUILAR H., VARGAS C. 1994. Phytophagous mites of Central America. CATIE. Turrialba, Costa Rica. 234 p.

OCHOA R., SALAS L.A. 1989. The genus Brevipalpus in Costa Rica (ACARI: Tenuipalpidae). International Journal of Acarology 15(1):21-30.

OCHOA R., SMILEY R.L., SAUNDERS J.L. 1991b. The family Tarsonemidae in Costa Rica (ACARI. Heterostigmata). International Journal of Acarology 17(1):41-86.

OZMAN-SULLIVAN S.K., AMRINE J.W. Jr., WALTER D.E. 2006. A new species of Eriophyoid mite (Acari: Eriophyidae) on sugarcane in Australia. International Journal of Acarology 32(4):387-395.

PEÑA J.E., MANNION C.M., HOWARD F.W., HOY M.A. 2007. Raoiella indica (Prostigmata: Tenuipalpidae): the red palm mite: a potential invasive pest of palms and bananas and other tropical crops of Florida, 2006. University of Florida IFAS Extension, ENY837. In: http://edis.ifas.ufl./pdfiles/IN/IN68100.pdf (05/04/12).

PRITCHARD A.E., BAKER E.W. 1955. A revision of the spider mite family Tetranychidae. Memoirs Series Vol. 2. Pacific Coast Entomological Society, San Francisco. 472 p.

PRITCHARD A.E., BAKER E.W. 1958. The false spider mites Acarina: (Tenuipalpidae). University of California Pub. Entomol. 14(3):175-274.

PUCHALSKA E. 2006. The influence of Oligonychus ununguis Jacobi (Acari: Tetranychidae) on photosynthetic activity and needle damage of Picea glauca 'Conica'. Biological Lett. 43 (2):353-360.

QUIROGA-MADRIGAL R.R., AGUILAR-ASTUDILLO E., MORALES-MORALES C.J., ROSALES-
ESQUINCA M.A., GIL-MARTÍNEZ G. 2010. Guía ilustrada de insectos y arañas asociados al piñón (Jatropha curcas L.) en Chiapas, México, con énfasis en la Depresión Central. Universidad Autónoma de Chiapas, Tuxtla Gutiérrez, Chiapas, México. 135 p.

RIVERO MALDONADO G., QUIRÓS M., SÁNCHEZ A., RODRÍGUEZ D., SANABRIA M.E., ORTEGA J., COLMENARES C. 2009. Determinación de la relación entre Brevipalpus phoenicis (Geijskes) y Dothiorella sp., en guayabo (Psidium guajava L.). Revista UDO Agrícola 9 (1):232-242.

RODA A., NACHMAN G., HOSEIN F., RODRIGUES J.C.V., PEÑA J.E. 2012. Spatial distributions of the red palm mite, Raoiella indica (Acari: Tenuipalpidae) on coconut and their implications for development of efficient sampling plans. Experimental and Applied Acarology 57:291-308.

RODRIGUES J.C.V., OCHOA R., KANE E. 2007. First report of Raoiella indica Hirst (Acari: Tenuipalpidae) and its damage to coconut Palms in Puerto Rico and Culebra Island. International Journal of Acarology 33(1):3-5.

SANABRIA C., AGUILAR H. 2005. El ácaro del vaneo del arroz, Steneotarsonemus spinki Smiley. Boletín Técnico Fitosanitario. Servicio Fitosanitario del Estado, Ministerio de Agricultura y Ganadería, San José, Costa Rica. 16 p.

TUTTLE D.M., BAKER E.W., ABBATIELLO M.J. 1974. Spider mites from Northwestern and North Central Mexico (Acarina: Tetranychidae). Smithsonian Contributions to Zoology Number 171. Smithonian Institution Press, Washington. 18 p.

TUTTLE D.M., BAKER E.W., ABBATIELLO M.J. 1976. Spider mites of Mexico (Acari: Tetranychidae). International Journal of Acarology 2(2):1-108.

URDANETA L., ARAUJO D., QUIRÓS M., RODRÍGUEZ D., COLMENARES C., POLEO N., PETIT Y., DORADO I. 2009. Micobiota endófita asociada a estadios preflorales del guayabo (Psidium guajava L.) y al ácaro plano (Brevipalpus phoenicis) (Geijskes) (Acari: Tenuipalpidae). Revista UDO Agrícola 9 (1):166-174.

VÁSQUEZ C., QUIROS de G.M., APONTE O., SANDOVAL D.M.F. 2008. First report of Raoiella indica Hirst (Acari: Tenuipalpidae) in South America. Neotropical Entomology 37(6):739-740. 